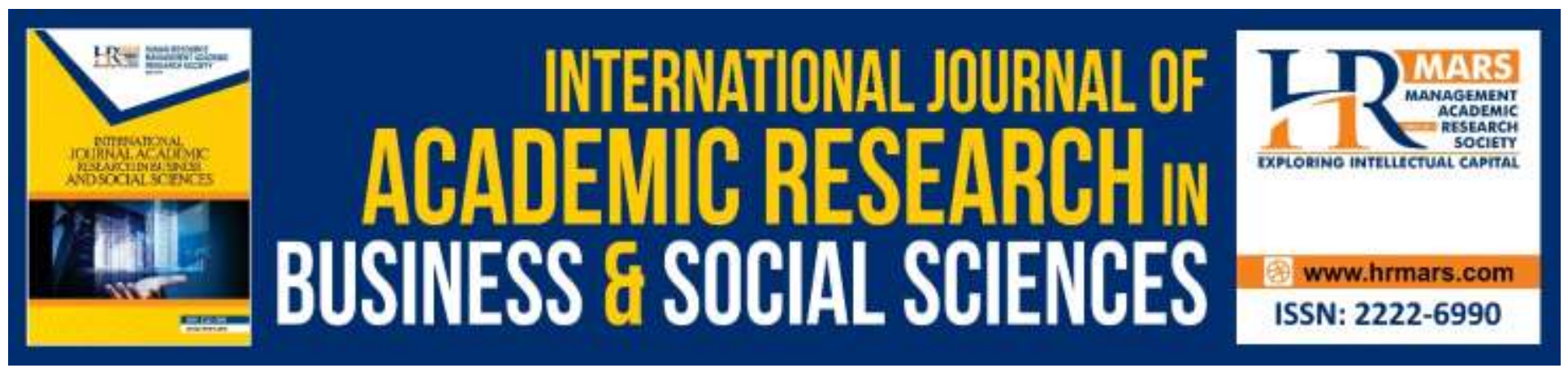

\title{
Teaching Mechanical Wave through Visualization Using Ruben's Tube
}

N. Alias, R. Julius, N. F. M. Sahapini, M. A. Yahya, Z. Mahfodz, F. F. Ramli, M. H. M. Khalid, F. Abdullah, F. A. Ab Haris, N. N. Mohd Yasin, W. A. L. Wan Ibrahim, P. A. F. Megat Mohd Azlan, M. N. Y. Muhamad Kherruldin.

To Link this Article: http://dx.doi.org/10.6007/IJARBSS/v9-i13/6241

DOI: 10.6007/IJARBSS/v9-i13/6241

Received: 26 March 2019, Revised: 27 May 2019, Accepted: 28 July 2019

Published Online: 29 August 2019

In-Text Citation: (Alias et al., 2019)

To Cite this Article: Alias, N., Julius, R., Sahapini, N. F. M., Yahya, M. A., Mahfodz, Z., Ramli, F. F., ... Kherruldin, M. N. Y. M. (2019). Teaching Mechanical Wave through Visualization Using Ruben's Tube. International Journal of Academic Research in Business and Social Sciences, 9(13), 44-53.

Copyright: (C) 2019 The Author(s)

Published by Human Resource Management Academic Research Society (www.hrmars.com)

This article is published under the Creative Commons Attribution (CC BY 4.0) license. Anyone may reproduce, distribute, translate and create derivative works of this article (for both commercial and non-commercial purposes), subject to full attribution to the original publication and authors. The full terms of this license may be seen

at: http://creativecommons.org/licences/by/4.0/legalcode

Special Issue: Revolutionizing Education: Challenges, Innovation, Collaboration, 2019, Pg. 44 - 53

http://hrmars.com/index.php/pages/detail/IJARBSS

JOURNAL HOMEPAGE

Full Terms \& Conditions of access and use can be found at http://hrmars.com/index.php/pages/detail/publication-ethics 


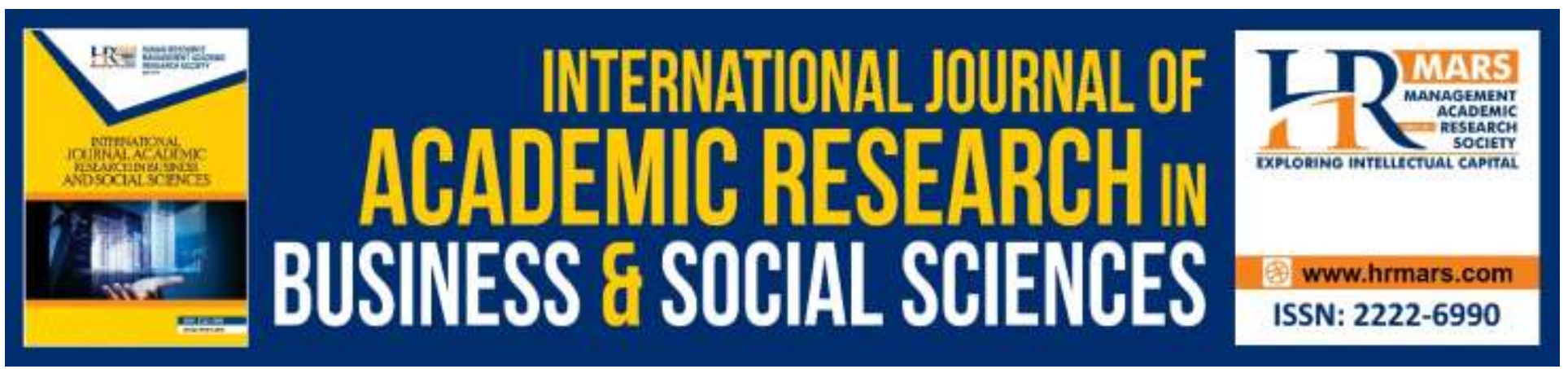

\title{
Teaching Mechanical Wave through Visualization Using Ruben's Tube
}

\author{
N. Alias, R. Julius, N. F. M. Sahapini, M. A. Yahya, Z. Mahfodz, F. F. \\ Ramli, M. H. M. Khalid, F. Abdullah, F. A. Ab Haris, N. N. Mohd \\ Yasin, W. A. L. Wan Ibrahim, P. A. F. Megat Mohd Azlan, M. N. Y. \\ Muhamad Kherruldin.
}

Faculty of Applied Sciences, Universiti Teknologi MARA, Perak Branch, Tapah Campus, Tapah Road, 35400 Perak, MALAYSIA

\begin{abstract}
In the science and physics syllabus, the topic of the wave is one of the important topics and should be mastered by the students. However, there are constraints in teaching where theoretical foundations cannot be directly visualized. The visualization method allows students to better understand the dynamic characteristics of the waves. Thus, we are innovating a Ruben tube for teaching and learning purposes in the topic of mechanical waves. The Ruben Tubes are a standard and acoustic instructional tool designed to understand the behavior of acoustic standing waves through the change of fire on the tube. In this study, relationships of nodes and anti-nodes flames numbers have also been exhibited directly and coincide with theory. Basic aspects of the wave also have been shown, such as wavelength and frequency relationships and velocities. The increase in frequency input value has shown flames with smaller wavelengths. From the findings, parameter relationships have been found numerically, ie the speed of sound in butane gas vs frequency: $y=$ $0.0029 x+276.08$, wavelength vs frequency: $y=-0.0007 x+0.9627$ and speed of sound in butane gas vs wavelength: $y=9.2576 x+272.49$.
\end{abstract}

Keywords: Mechanical Wave, Ruben's Tube

\section{Introduction}

Research-based learning has been widely recommended for educational institutions as a innovative method to teach science subjects. The teaching approach with this method encourages students to conduct investigations and experiments by following the scientific steps to find answers and solutions for the proposed problem. Many science-education programs and projects have been organized for science-based inquiries based on investigations in educational institutions (Geier et al., 2008; Linn, Clark, \& Slotta, 2003; Songer, Lee, \& Kam, 2002; Songer, Lee, \& McDonald, 2003). There have also 
been numerous studies and discussions conducted on science teaching methods by deferring answers to students and instead asking them to get answers through their own "hands-on" and "inquiry based" inquiry (Hmelo-Silver, Duncan, \& Chinn, 2007; Klahr \& Nigam, 2004; Kuhn, 2007; Matlen \& Klahr, 2013).

The syllabus about waves is a fundamental topic for science and physics subjects. From the feedback received, the students experience difficulty in visualizing the wave structure and its characteristics. This teaching innovation is made to assist the teaching and learning process as well as to study more about sound in the form of visual standing waves. This stand wave is formed when the sound frequency is applied to the speaker connected to the pipe. The vibration of sound frequency flows from the speakers to the balloon and balloon vibration changes the pressure on the gas butane particles inside the pipe. This will overcome different gas pressure in a particular place in the tube that will form a standing wave.

The Ruben Tube concept was designed by Heinrich Rubens, a German physicist who was born in 1865 and his friend John Le Conte has discovered that sounds have an effect on fire (Rubens \& Krigar-Menzel, 1905). The speed of the sound is varied through its medium and temperature. In the air, the sound speed at $0^{\circ}$ is $331 \mathrm{~m} / \mathrm{s}$ and at $20^{\circ}$ is $343 \mathrm{~m} / \mathrm{s}$. Both the speed of sound in the air are usually used in relevant mathematical problems. We want to identify the speed of sound in butane as there are many different types of gas mediums that have different characteristics.

Most researchers use propane or methane gas as their gas medium (Gardnerb, 2009). It makes our project different from them because we use different gas butane gas. Sound is generated from air compression and decompression processes, or any medium it passes (Halliday, Resnick, \& Walker, 2000). The sound played through the tube with the holes at the top of the pressure will go through the decompression process which causes the gas to flow through the different holes at the top of the pipe to undergo different pressures then produce different heights. The basic equation of the wave, $v=f \lambda$ is used together with its use in relation to the closed pipe harmonic frequency $(\lambda=4 L$, base frequency $=v / 4 \mathrm{~L}$ ). The harmonic frequency or first base frequency is a node that has a wavelength of four times along the pipe.

The number of nodes and anti-nodes generated along the tube wave depends on the harmonic frequency of the wave. With every change in the harmonic, the number of nodes and anti nodes will increase with $(n+1) / 2$. The schematic diagram of the formation of node and anti-node in the Rubens Tube is shown in Figure 1. When the speaker makes a sound, the wave standing inside the tube produces nodes and anti-nodes. The oscillating pressure caused by the sound wave will cause less gas to come out and produce nodes while the points with stable pressure will produce anti-nodes (maxima) waves (Figure 2). Gas is difficult to move on nodes then it will produce small fires while antinodes experiencing maximum displacement and the gas will produce a higher fire. 


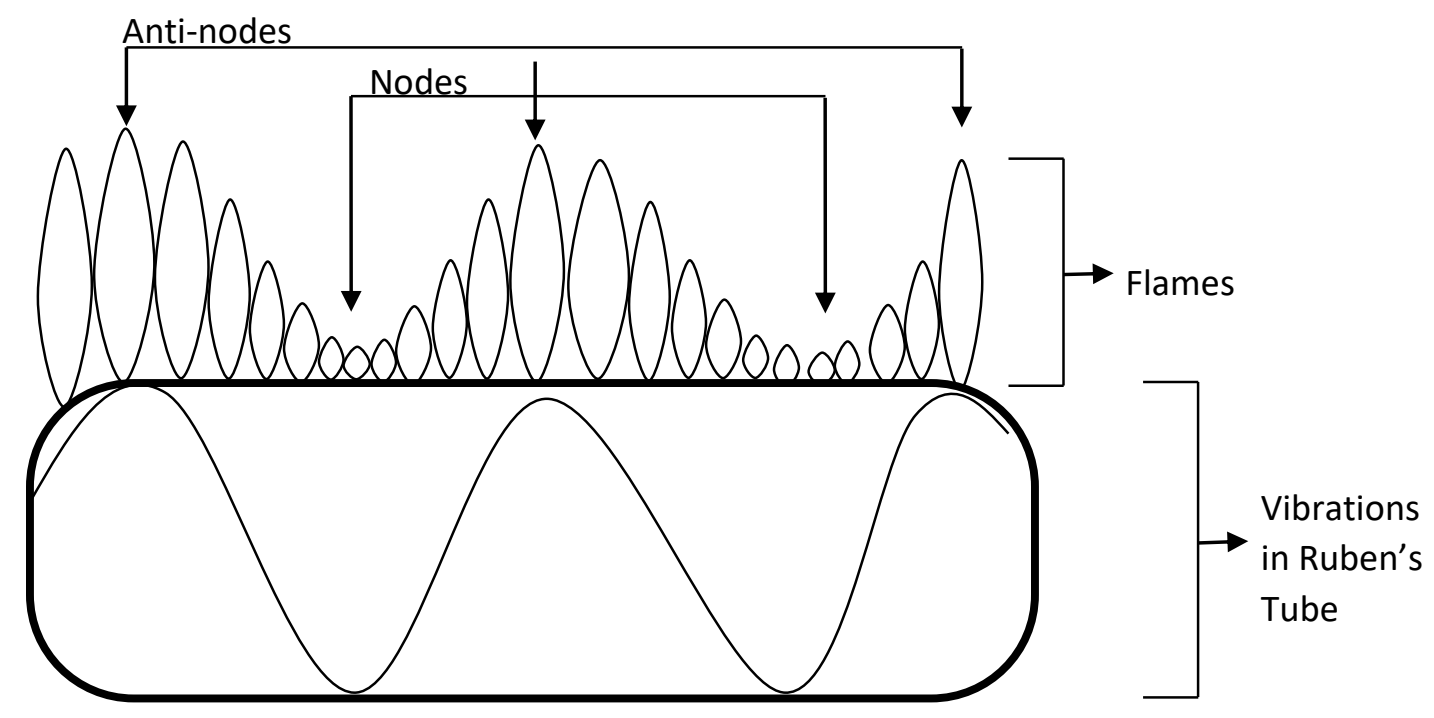

Figure 1. Formation of Nodes and Anti-nodes at the Ruben's tube

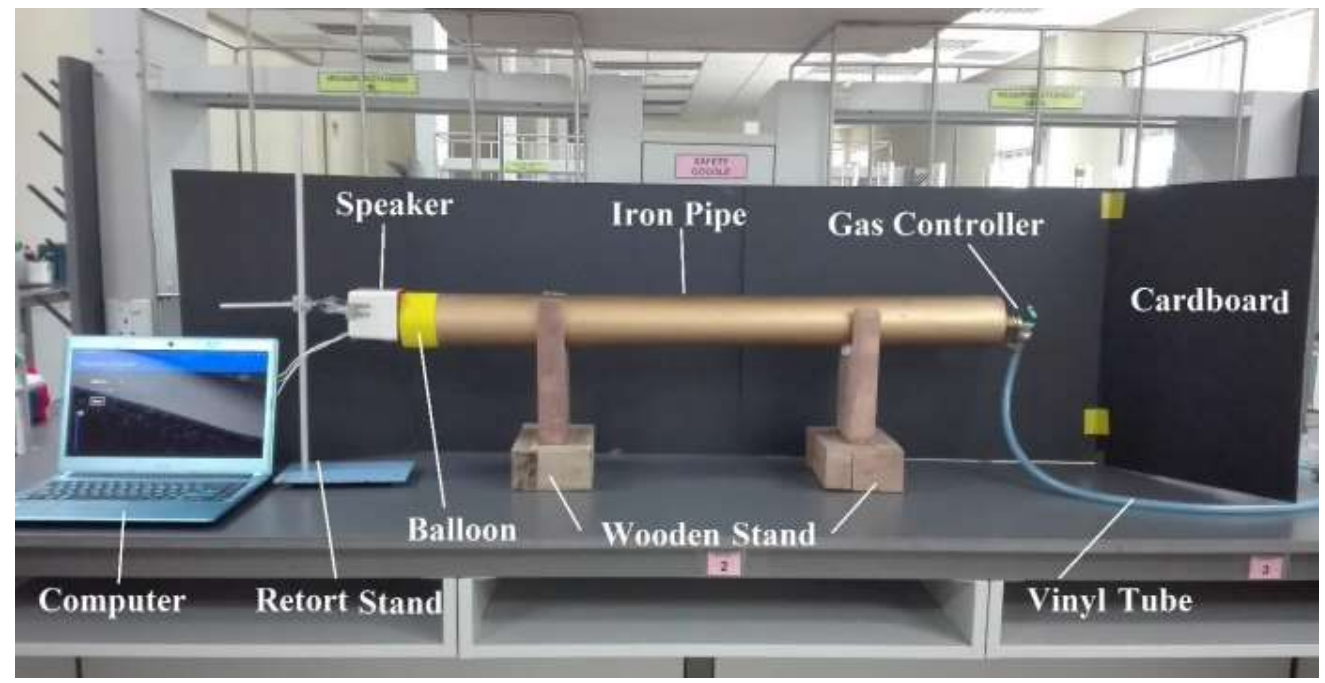

Figure 2. The proposed Ruben's Tube setup that has been implemented in this research.

\section{Methodology}

Methods are listed in the following order as follows and followed by a list of pictures arranged according to the actual sequence of the study, as shown in Figure 3. After the setup has completed, the sound inputs that have the frequencies of the human hearing range are selected, which in the range between $200 \mathrm{~Hz}$ to $2000 \mathrm{~Hz}$. 

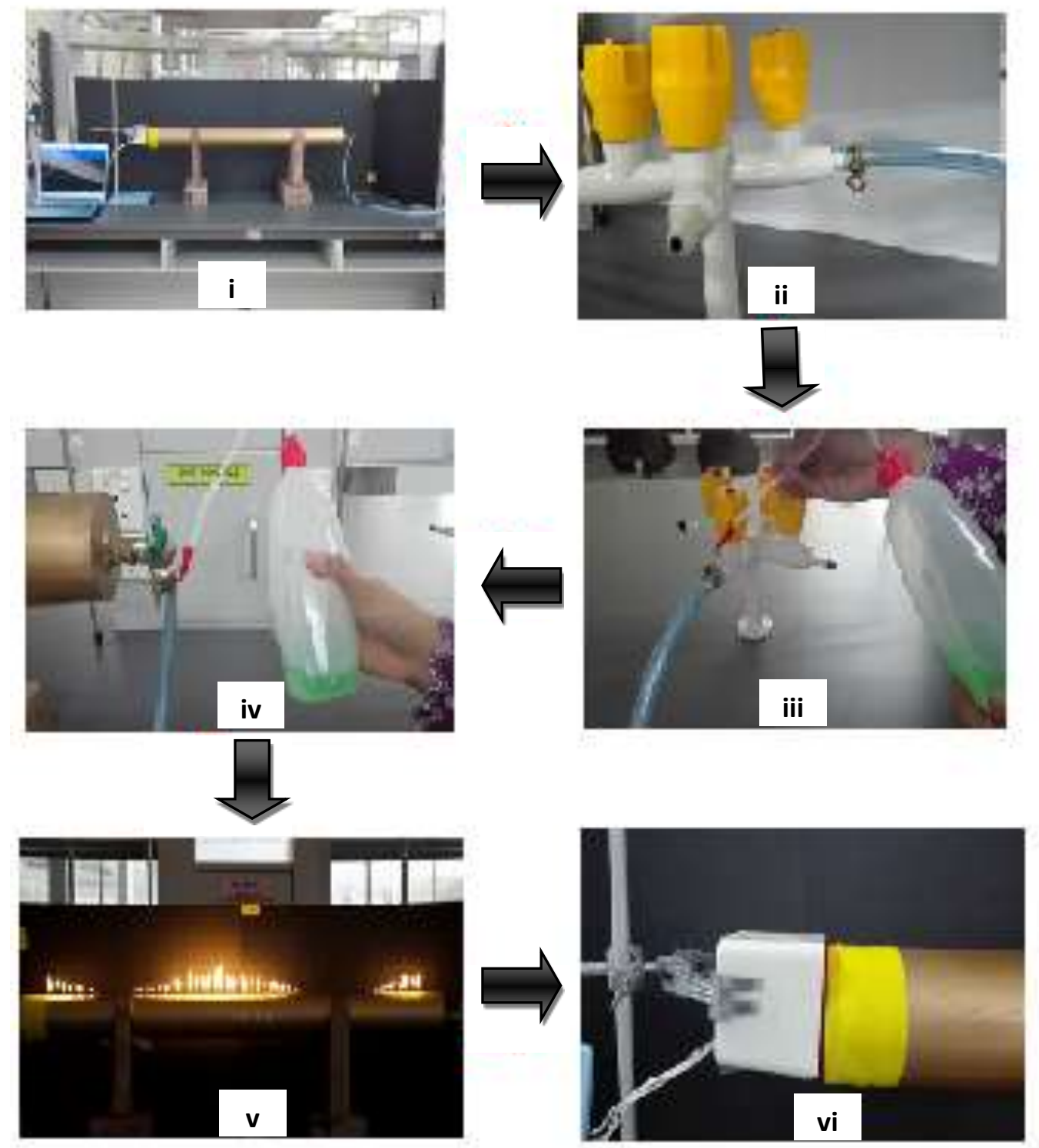

Figure 3. Flow chart of the research methodology, (i) The iron pipe was placed on the two wooden stands, (ii) Vinyl tube was tightly connected to the gas supply, (iii) Liquid soap was being spread on the vinyl tube that was connected to the gas supply to ensure that there is no gas leakage, (iv) Gas supply and controller was opened to allow butane gas entering the iron pipe. Let the gas filled the tube for a few minutes before ignited it, ( $v$ ) The gas was ignited by using a fire starter, (vi) A speaker was being positioned at the opened end of the iron pipe which was tightly covered with a balloon. 
INTERNATIONAL JOURNAL OF ACADEMIC RESEARCH IN BUSINESS AND SOCIAL SCIENCES

Vol. 9, No. 13, Special Issue: Revolutionizing Education: Challenges, Innovation, Collaboration., 2019, E-ISSN: 2222-6990 @ 2019 HRMARS

\section{Results and Data Analysis}

Figure 4: shows examples of the obtained standing waves in different frequencies.

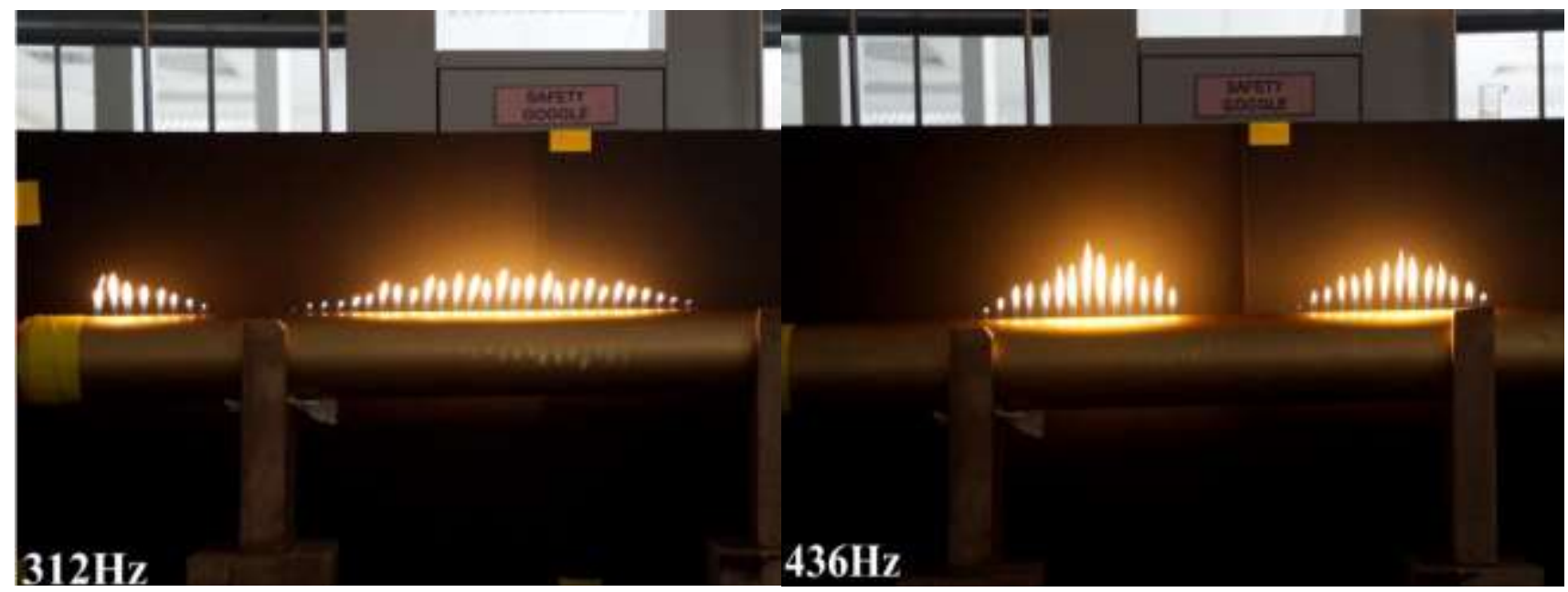

i.

ii.

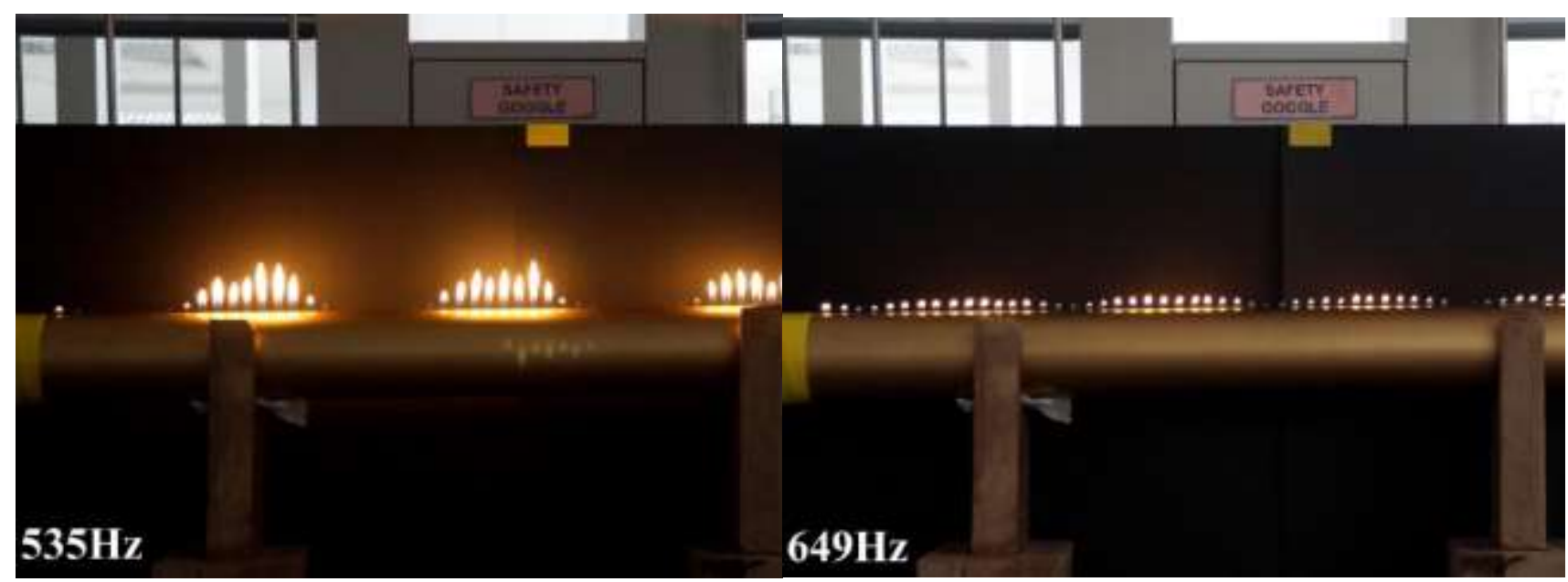

iv.

iii. 


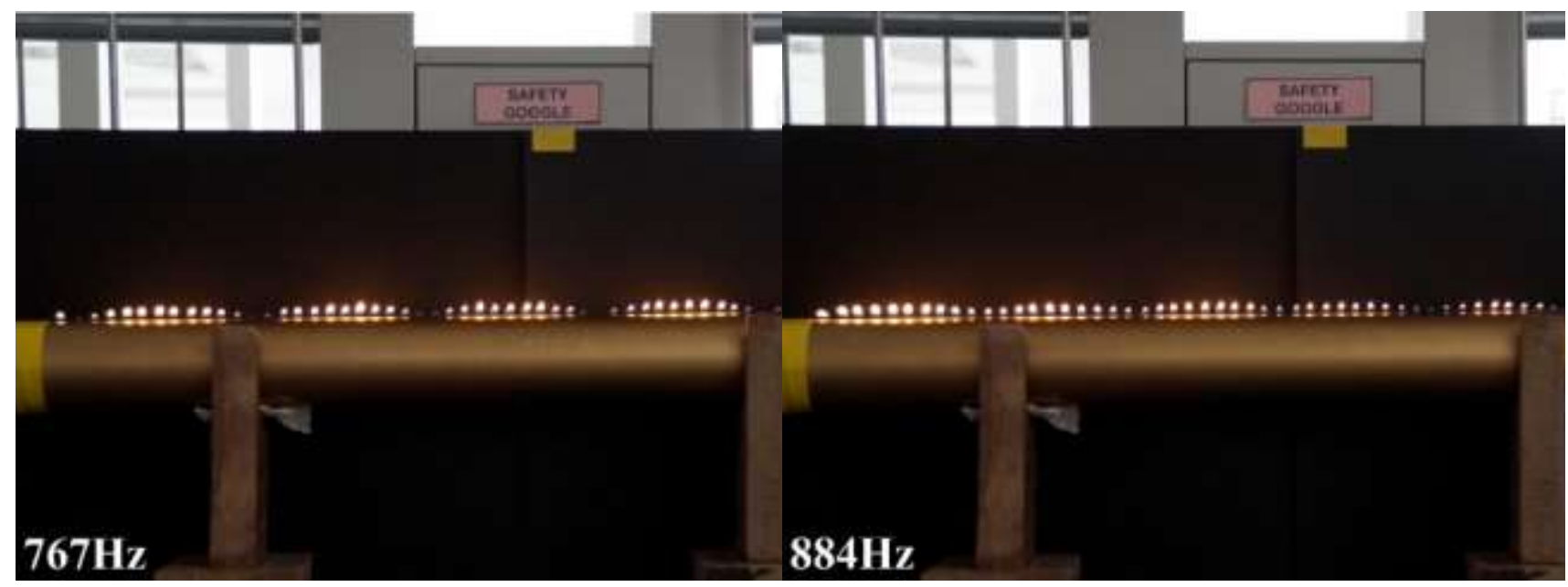

V.

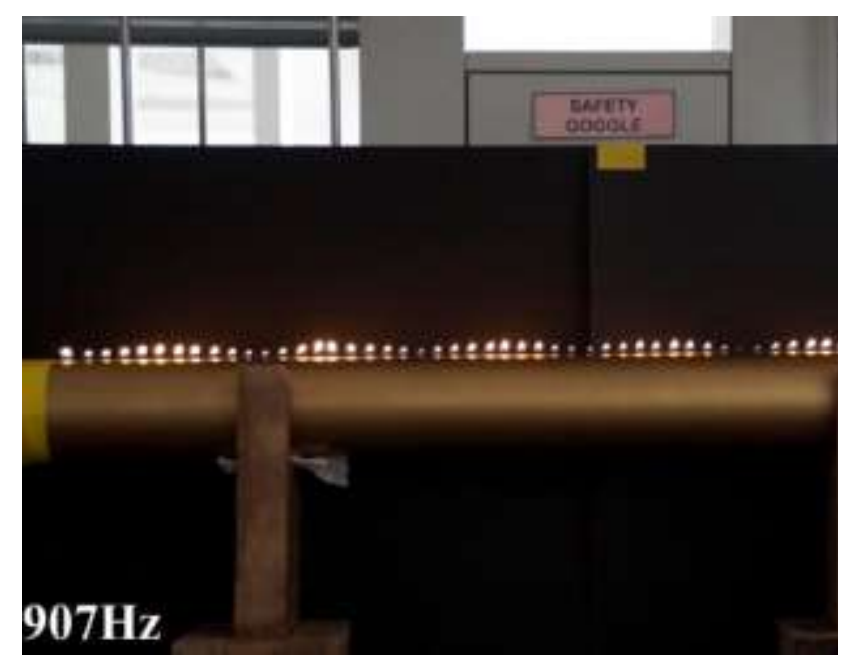

vii. vi.

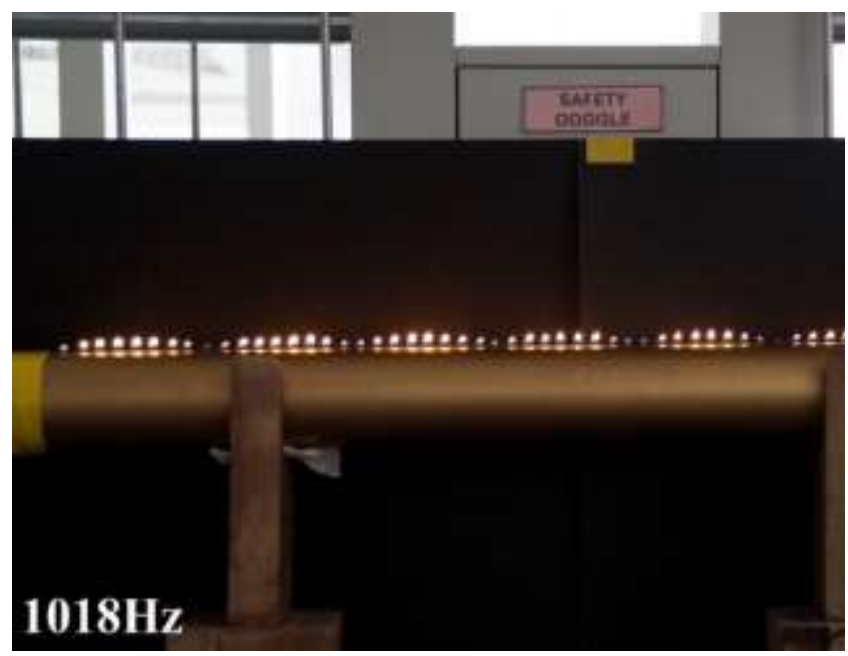

viii.

Figure 4. Standing waves at different frequencies which are at (i) $312 \mathrm{~Hz}$, (ii) $436 \mathrm{~Hz}$, (iii) $535 \mathrm{~Hz}$, (iv) $649 \mathrm{~Hz}$, (v) $767 \mathrm{~Hz}$, (vi) $884 \mathrm{~Hz}$, (vii) $907 \mathrm{~Hz}$ and (viii) $1018 \mathrm{~Hz}$.

Based on the results obtained, students can easily relate the knowledge of wave properties, as instance, it shows that the greater the frequency of sound used as input, the smaller the resulting wavelength of the output, which is the visualize flame. This coincides with the basic theory of the wave which states that the wavelength is inversely proportional to the frequency. Furthermore, each frequency is related with different standing wave pattern which are refer as harmonics, $\mathrm{n}$ or can be known by knowing the total of antinodes of the standing waves. From the live visualization, students can have clearer understanding on mathematical relationship for length $(L)$-wavelength $(\lambda)$ harmonics where in general, $n$th harmonic: $L=(n / 2) \lambda$. 
Besides, the equation speed $(v)=$ frequency $(f) \times$ wavelength $(\lambda)$ is used to find the speed of sound in the butane gas. It states the linear mathematical relationship between the speed ( $v$ ) of a wave with the wavelength $(\lambda)$ and the frequency $(\mathbf{f})$. The frequency of the sound was adjusted to going through the tube and then the wavelength was measured when the standing wave is formed.

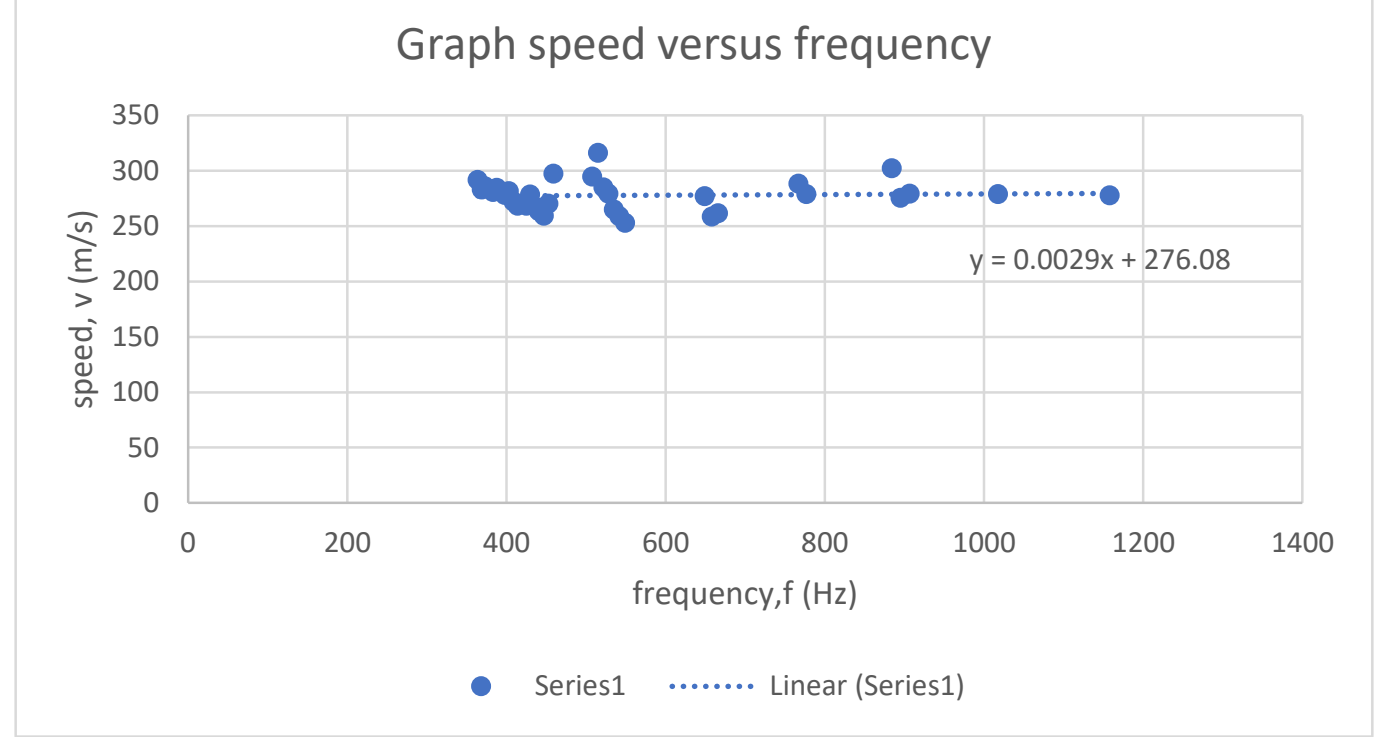

Figure 5. Graph of Speed vs Frequency

According to the Figure 5, the graph speed versus frequency shows that speed of sound in butane is directly proportional to the frequency of sound in $\mathrm{Hz}$ unit. For that graph, the function that being calculated is $y=0.0029 x+276.08$. The value of 0.0029 shows the relationship between frequency of sound and speed of sound in butane.

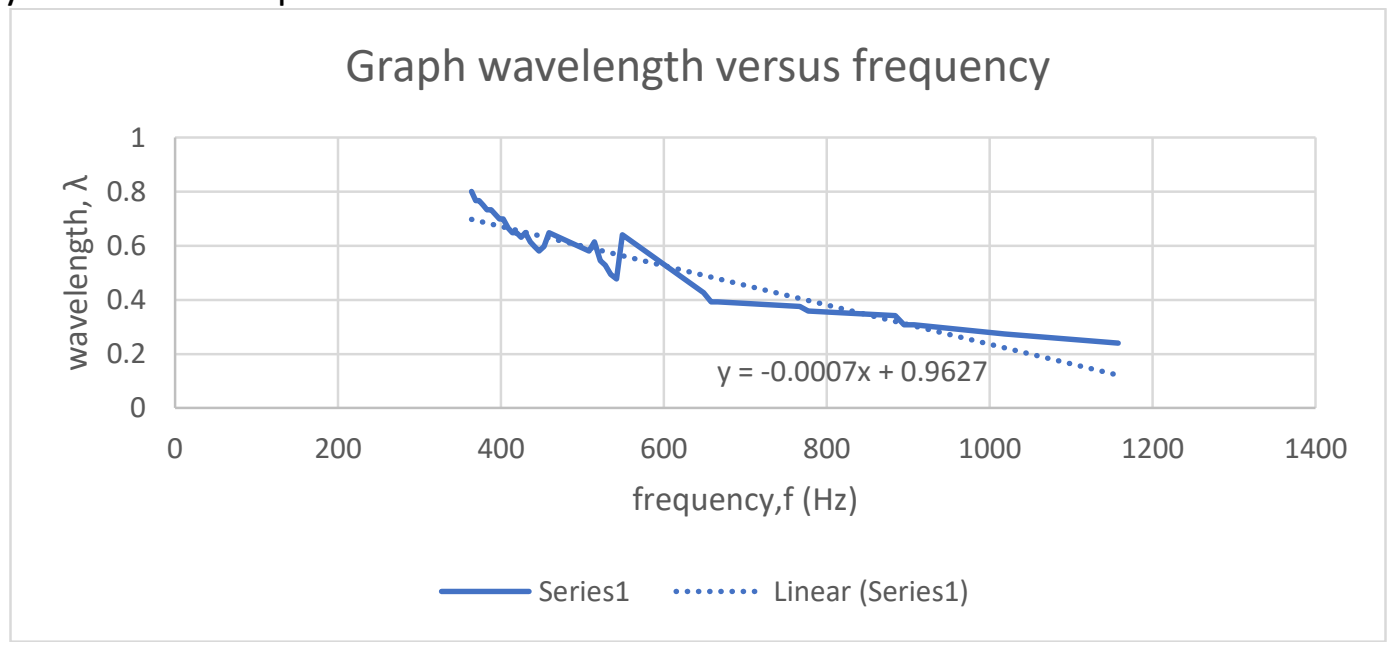

Figure 6. Graph of Wavelength vs Frequency

While according to the Figure 6, the graph of wavelength versus frequency exhibits that the wavelength of standing wave is inversely proportional to the frequency of the sound in $\mathrm{Hz}$ unit. The mathematical function that being obtained from the graph is $y=-0.0007 x+0.9627$. The value of 0.0007 shows the relationship between wavelength of standing wave and frequency of sound based on function. 


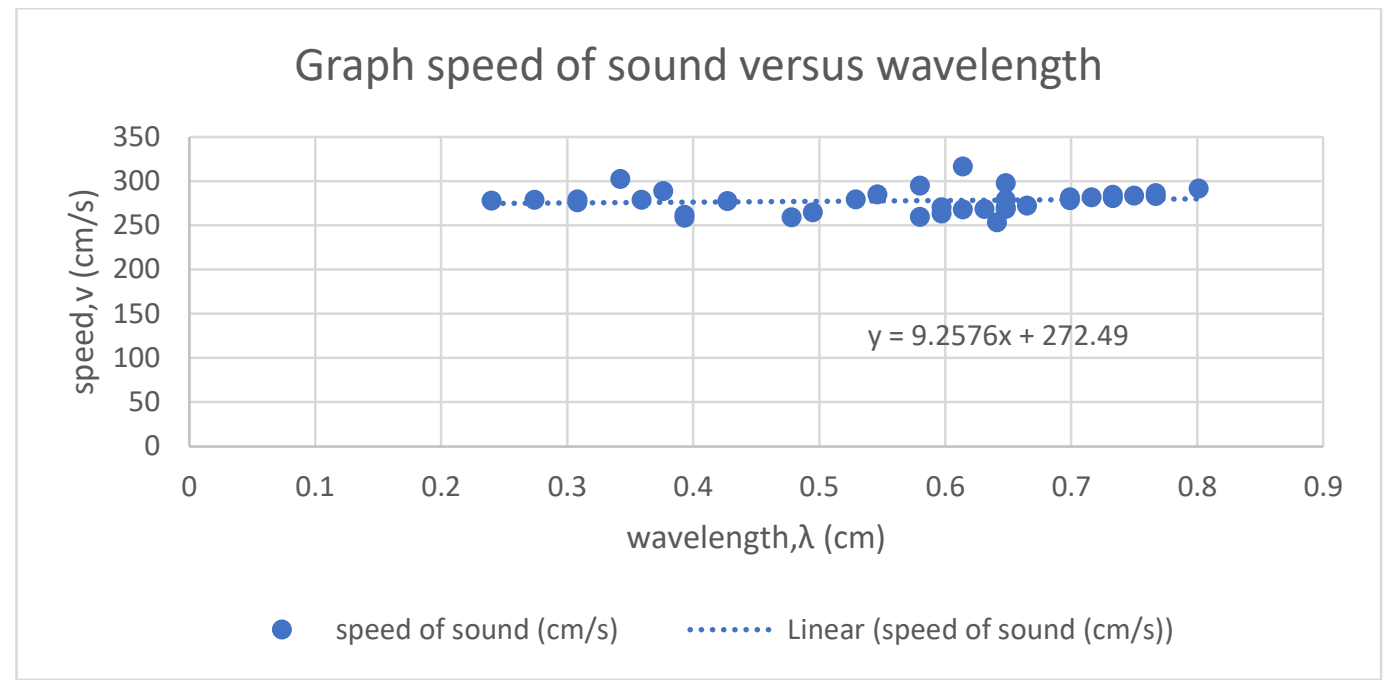

Figure 7. Graph of Wavelength vs Frequency

For Figure 7, graph speed versus wavelength shows that speed of sound in butane is directly proportional to the wavelength of standing wave and the function that obtained from the graph is $y$ $=9.2576 x+272.49$. The value of 9.2576 shows the relationship between speed of sound and wavelength of standing wave.

\section{Conclusion}

The innovative Ruben's tube has been successfully and accurately demonstrated in visualization of the basic features of waves such as nodes and anti-nodes, as well as velocities, frequencies and wavelengths. In a more advanced environment, tubes can be used as a parallel impedance demonstrations or samples of acoustic mass. This study has shown the nodes and antinodes of the flames which are correlate with the wavelength. In addition, the basic features of the wave have also been demonstrated directly, such as the relationship between wavelength, frequency and velocity. Additionally, an increase in frequency input values exhibit fire with smaller wavelengths. Numerically, the speed of sound in butane gas are dependent to the frequency, which are the speed of sound in butane gas vs frequency: $y=0.0029 x+276.08$; wavelength vs frequency: $y=-0.0007 x+$ 0.9627; and speed of sound in butane gas vs wavelength: $y=9.2576 x+272.49$. In the future, this research can be expanded more by varying the variable such as temperature and pressure.

\section{References}

Bowman, K. (2011). Determining the Speed of Sound in Propane with a Rubens tube: The Menlo Roundtable.

Geier, R., Blumenfeld, P. C., Marx, R. W., Krajcik, J. S., Fishman, B., \& Soloway, E. (2008). Standardized test outcomes for students engaged in inquiry-based science curricula in the context of urban reform. Journal of Research in Science Teaching, 45(8), 922-939.

Halliday, D., Resnick, R., \& Walker, J. (2000). Fundamental of Physics: Wiley.

Hmelo-Silver, C. E., Duncan, R. G., \& Chinn, C. A. (2007). Scaffolding and achievement in problembased and inquiry learning: A response to Kirschner, Sweller, and Clark. Educational Psychologist, 42(2), 99-107. 
Klahr, D., \& Nigam, M. (2004). The equivalence of learning paths in early science instruction effects of direct instruction and discovery learning. Psychological Science, 15(10), 661-667.

Kuhn, D. (2007). Is direct instruction an answer to the right question? . Educational Psychologist, 42(2), 109-113.

Linn, M. C., Clark, D., \& Slotta, J. D. (2003). WISE design for knowledge integration. Science Education, 87(4).

Matlen, B. J., \& Klahr, D. (2013). Sequential effects of high and low instructional guidance on children's acquisition of experimentation skills: Is it all in the timing? . Instructional Science, 41(3), 621-634.

Michael, D., Gardnerb, K. L. (2009). An Investigation of Rubens Flame Tube Resonances. Acoustical Society of America, 4.

Rubens, H., \& Krigar-Menzel, O. (1905). Flammenröhre für akustishe beobachtungen (Flame tube for acoustical observations). Ann. Physc., 322, 149-164.

Songer, N. B., Lee, H.-S., \& Kam, R. (2002). Technology-rich inquiry science in urban classrooms: What are the barriers to inquiry pedagogy? Journal of Research in Science Teaching, 39(2), 128-150.

Songer, N. B., Lee, H. S., \& McDonald, S. (2003). Research towards an expanded understanding of inquiry science beyond one idealized standard. Science Education, 87(4), 490-516. 